\title{
Non-technical Skills Simulation Training
}

\author{
Jennifer C. Magill ${ }^{1} \cdot$ Neil Tolley $^{1}$
}

Published online: 7 February 2020

(C) The Author(s) 2020

\begin{abstract}
Purpose of Review "Non-technical skills" are critical to patient safety and form an important part of a surgeon's competency. Inter-disciplinary team training is now considered essential to train these valuable skills. This review discusses the importance of non-technical skills, and the role these skills have in simulation training within Otolaryngology.

Recent Findings Otolaryngologists are uniquely positioned to encounter airway emergencies. Consequently, team-based training in crisis scenarios is especially important. Simulation can occur in situ or in the simulated setting, with "boot-camps" becoming a popular training intervention. Whilst team training within otolaryngology has been shown to be highly effective, formal assessment of these skills is not currently routine, with no assessment tool specifically tailored to ENT.

Summary Simulation-based training is an effective and feasible method of teaching non-technical skills in Otolaryngology. With the shift towards competency-based medical education, formal assessment of these skills is important to perform.
\end{abstract}

Keywords Non-technical skills $\cdot$ Human factors $\cdot$ Team-training $\cdot$ Otolaryngology $\cdot$ Simulation $\cdot$ Medical education

\section{Introduction}

Simulation-based training now forms an essential part of modern day medical education. With an increasing emphasis on patient safety and the truncated working hours due to the European Working time directive, simulation offers an environment in which today's trainees can gain the necessary competences in a safe blame-free environment. Whilst traditional simulation training programmes have focused on the individual expertise of the operating surgeon, this alone is insufficient for achieving safer surgery. Studies have shown that nontechnical skills (communication, teamwork, leadership and situation awareness) are the leading cause for adverse events in the operating theatre, with poor communication found to be a factor in $43 \%$ of errors made in surgery [1]. Consequently,

This article is part of the Topical Collection on Simulation Training in Otolaryngology

Jennifer C. Magill

Jennifer_magill22@hotmail.com

Neil Tolley

n.tolley@imperial.ac.uk

1 Imperial College Healthcare NHS Trust, St Mary's Hospital, London, UK training of surgeons in non-technical skills is becoming increasingly important.

This review article will focus on the background to nontechnical skills in the healthcare system, the role of nontechnical skills in surgical training and the current and future role of team-based simulation training in otolaryngology.

\section{Setting the Scene}

\section{Patient Safety and Modern Surgical Practice}

The landmark report by the Institute of Medicine entitled "To Err is Human" [2••], and the UK equivalent "an organization with a memory" [3], reported that between $44,000-98,000$ deaths occurred each year from medical errors that could have been prevented. Subsequent studies have shown that surgical patients are particularly at risk $[4,5]$ with $44 \%$ of all adverse events occurring in the operating room [5].

\section{Non-technical Skills}

Non-technical skills or "human factors" are the cognitive (decision-making and situational awareness) and interpersonal skills (communication, teamwork and leadership) which underpin technical competence [6]. Root cause analysis of 
adverse events in healthcare has revealed that it is failure of these non-technical skills, rather than lack of technical proficiency, which leads to bad outcomes in the operating theatre. They are now considered key to delivering safe surgical practice and improving patient safety.

\section{Simulation in Surgery}

Simulation has traditionally been used for training technical skills, and has various applications in otolaryngology; temporal bone labs and the ovine model for endoscopic sinus surgery [7] are established validated examples. Simulation can also be used to train non-technical skills. The aviation industry has led the way with regard to simulation-based team training, with the advent of "Crew Resource Management" (CRM); the aim of which is to train the individual with team working skills whilst training teams to work together in the most effective manner. These skills can then be used in simulated crisis scenarios. This has been adopted with great success in Anaesthesia and in 2011 the Association of Surgeons in Training (ASiT) endorsed high-quality simulation for the training of surgeons. It also forms part of the Intercollegiate Surgical Curriculum Programme (ISCP). Consequently, there has been a dramatic increase in the amount of non-technical skills training in surgery, including Otolaryngology.

Surgery is a high-stakes, high-pressure profession, relying quite often on experiential learning and requiring high levels of teamwork and leadership, particularly in a crisis situation. Unfortunately, "never events" such as an airway fire, or wrong-side surgery do occur and the surgeon is expected to manage these scenarios effectively despite little or no experience. Simulation allows trainees to be exposed to a range of tasks outside the level of their competence and provides the platform in which these rare situations can be repeatedly reproduced with no risk to patient safety.

Traditionally, healthcare professionals have trained separately despite working together on a daily basis. Crisis situations rely heavily on the ability of the healthcare team to perform well together in a stressful environment, and it is hardly surprising therefore that teamwork features heavily as a cause for error in the operating theatre. Consequently, the importance of multidisciplinary team-based training has been highlighted, but despite this there is very little reported in the literature.

\section{Team-Based Simulation Training in Otolaryngology}

As surgeons, Otolaryngologists should be aware of the importance that non-technical skills play in the day to day outcomes of our patients. A review on patient safety within Otolaryngology [8] reported that whilst the specialty shared common safety concerns with other surgical specialties, there were risks unique to the specialty, airway and thyroid surgery being most notable. The incidence of serious airway complications occurring in the UK was particularly highlighted by The 4th National Audit Project by the Royal College of Anaesthetists (NAP4) [9, 10]. Airway incidents for head and neck surgical patients featured frequently, and the report recommended greater collaboration in team training between anaesthetists and otolaryngologists in particular.

Although non-technical skills training in Otolaryngology is a relatively new concept, there is an increasing amount of simulation activity within the literature. However, despite this, a recent cross-sectional survey by Dean et al. in 2019 [11] to all Otolaryngology residency programme directors, in the USA and Porto Rico, revealed that $76 \%$ of programme directors did not think it was important to include training in nontechnical skills at training boot camps.

Whilst the majority of published literature focuses on the trainee as the main participant in simulation scenarios, there are a handful of training programmes which have involved all members of the operating team to produce a truly multidisciplinary team training exercise [12-14].

\section{Common Characteristics of Otolaryngology Team-Based Training}

\section{Setting}

Non-technical skills team simulation can be performed in a simulated setting [15-17] (such as a simulation suite or simulated operating theatre) or in situ at the point of clinical care [12] (e.g. operating theatre, ICU). Whilst in situ simulation has the distinct advantage of increased realism, a high-fidelity simulated setting to replicate either an operating theatre (as seen in Fig. 1) or ICU can also provide a high degree of face validity, which is important in order to engage the team participants.

A number of studies have reported "boot camp" style training days $[15,16,18-20]$, with a high-fidelity team simulation performing part of a larger intense training day into ENT skills. This is proving a popular training intervention and has been successful in the USA [19], Canada [16] and more recently the UK [20]. Feedback from trainees have shown boot camps to be highly effective at improving confidence levels when managing emergencies [18].

\section{Simulation Scenarios}

Important considerations for simulation scenarios include:

1. The scenario is sufficiently engaging to all team members; this is particularly important for multidisciplinary 


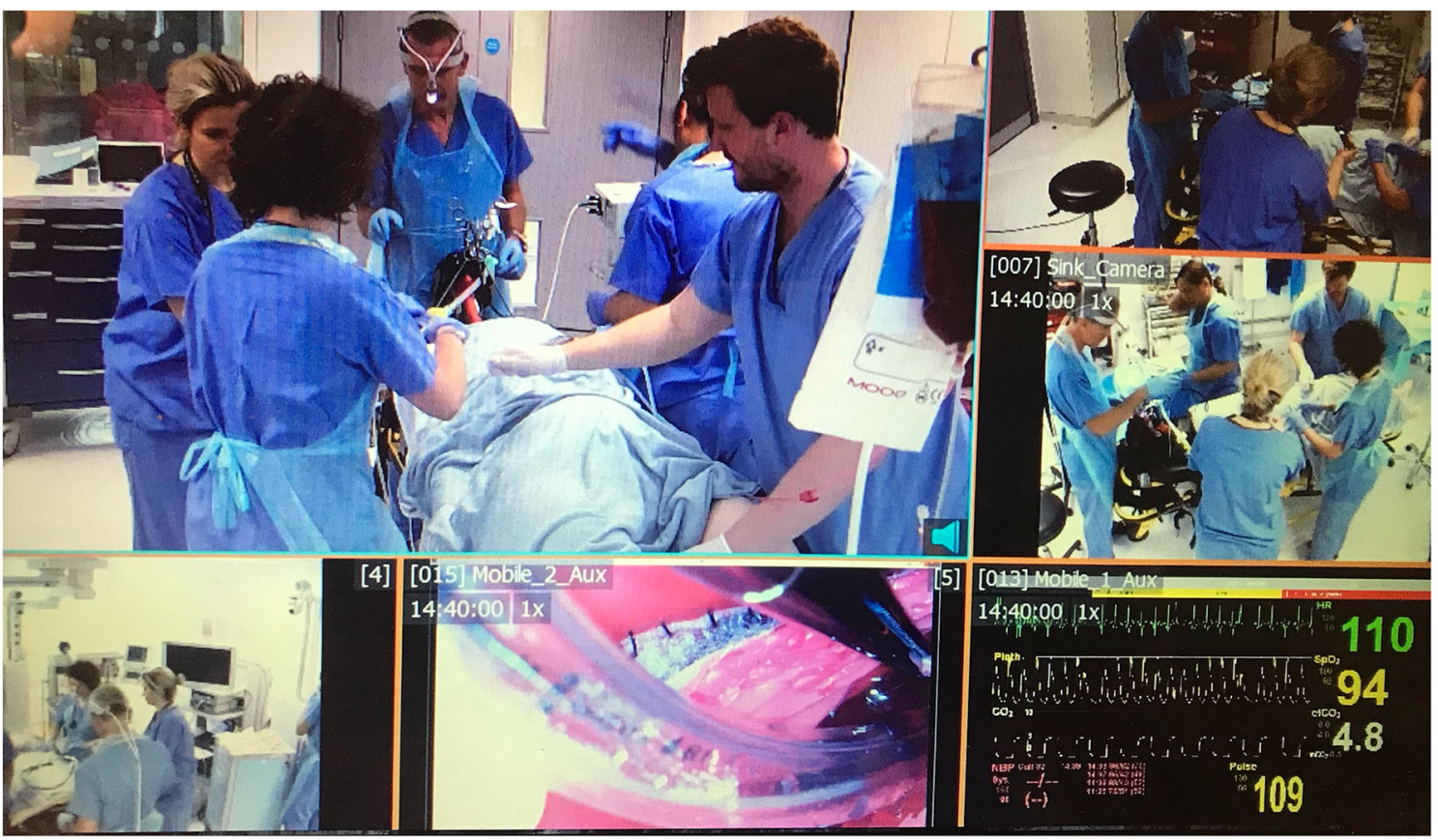

Fig. 1 High-fidelity simulated operating theatre to train team skills

Table 1 Behavioural marker tools used to assess non-technical skills in surgery

\begin{tabular}{|c|c|c|c|c|}
\hline Assessment tool & Population & $\begin{array}{l}\text { Non-technical skills } \\
\text { assessed }\end{array}$ & Validity & Reliability \\
\hline $\begin{array}{l}\text { Non-Technical Skills of } \\
\text { Surgeons (NOTSS) [23] }\end{array}$ & Surgeons & $\begin{array}{l}\text { 1. Situational Awareness } \\
\text { 2. Decision-making } \\
\text { 3. Communication and } \\
\text { teamwork } \\
\text { 4. Leadership }\end{array}$ & Yes - content & $\begin{array}{l}\text { Yes-inter-rater reliability } \\
\text { and internal consistency }\end{array}$ \\
\hline Revised NOTECHS [22] & $\begin{array}{l}\text { Surgeons } \\
\text { Anaesthetists } \\
\text { Nurses } \\
\text { ODP's }\end{array}$ & $\begin{array}{l}\text { 1. Communication and } \\
\text { interaction } \\
\text { 2. Vigilance and } \\
\text { situational awareness } \\
\text { 3. Team skills } \\
\text { 4. Leadership and } \\
\text { management skills } \\
\text { 5. Decision-making- } \\
\text { surgical crisis }\end{array}$ & $\begin{array}{l}\text { Yes - content } \\
\text { Yes - construct significant difference in } \\
\text { NOTECH scores seen with increasing } \\
\text { seniority }\end{array}$ & $\begin{array}{l}\text { Yes - internal consistency } \\
\text { Yes - inter-rater reliability }\end{array}$ \\
\hline $\begin{array}{l}\text { Oxford NOTECHS } \\
\text { (I and II) }[24,25]\end{array}$ & $\begin{array}{l}\text { Surgeons } \\
\text { Anaesthetists } \\
\text { Nurses }\end{array}$ & $\begin{array}{l}\text { 1. Communication and } \\
\text { interaction } \\
\text { 2. Situational awareness } \\
\text { 3. Teamwork and } \\
\text { cooperation } \\
\text { 4. Leadership and } \\
\text { management } \\
\text { 5. Decision-making }\end{array}$ & Yes - construct & Yes-inter-rater reliability \\
\hline $\begin{array}{l}\text { Observational Teamwork } \\
\text { Assessment for Surgery. } \\
\text { (OTAS) } \\
{[26]}\end{array}$ & $\begin{array}{l}\text { Operating } \\
\text { theatre } \\
\text { teams }\end{array}$ & $\begin{array}{l}\text { 1. Communication } \\
\text { 2. Leadership } \\
\text { 3. Cooperation and } \\
\text { back-up behaviour } \\
\text { 4. Coordination } \\
\text { 5. Team monitoring and } \\
\text { situational awareness }\end{array}$ & $\begin{array}{l}\text { Yes - content } \\
\text { Yes - construct }\end{array}$ & Yes-inter-rater reliability \\
\hline
\end{tabular}


simulation, ensuring that there are enough tasks or incidences to challenge all specialties.

2. Scenario fits the ability and grade of trainee

3. Scenario is realistic; examples may be adapted from actual cases.

Airway emergencies lend themselves well to team-based training, with active and engaging roles for all specialties: surgeons, nurses and anaesthetists. Other examples of simulated scenarios in the literature include post-thyroidectomy bleeding [19], post tonsillectomy bleed [17], paediatric inhaled foreign body [21•], airway fire [17], neck stabbing and facial trauma $[16,21 \bullet]$.

\section{Assessment}

Assessment should form a fundamental and necessary component of all training interventions, and with the shift towards a more competency-based approach, this is especially important and necessary. Within surgery, a variety of behavioural marker systems have been used to evaluate non-technical skills [22-26] (see Table 1), including Non-Technical Skills for Surgeons (NOTSS) [23], and The Non TECHnical Skills scale (NOTECHS) [22]. No one tool is considered "gold standard" and it is important to remember that such tools are highly context specific. It is also particularly important to note that assessment tools should be psychometrically robust. Although not specifically designed for ENT surgery, NOTSS has been used to assess non-technical skills in Otolaryngology trainees, and has been shown to be feasible, and reliable [21•]. Ideally, a similarly robust tool tailored to the needs of ENT training should be developed.

\section{Debrief}

Debriefing is one of the most important parts of simulation and is perhaps the one area where simulation has an advantage over a real clinical emergency. In the workplace, feedback and debrief can routinely be forgotten or happen haphazardly; the team is often too busy and distracted following a crisis to debrief in the acute aftermath. In medical simulation, however, feedback is mandatory and immediate, and errors are a valuable part of the learning experience.

\section{Effectiveness of Team Training in Otolaryngology}

Non-technical skills training in otolaryngology appears to be well received by trainees, with multiple studies in the literature reporting a positive reactionary response from participants
[13, 14, 18, 19]. Confidence levels in managing Otolaryngology emergencies have also been shown to increase following simulation training [13, 17-19, 27] and a randomized control trial by Smith et al. in 2015 showed that trainees randomized to scenario simulation performed significantly better in clinical scenario vivas than those given lecture-based training [28]. Team training can also have a positive impact at an organizational level; Metha et al. [29] reported reduced airway mortality following the introduction of a multidisciplinary airway simulation course at their institution.

\section{Conclusion}

Non-technical skills are of increasing importance. In particular, Otolaryngologists are likely to encounter airway emergencies within the operating theatre and therefore need to be equipped with exemplary inter-disciplinary teamwork, leadership and communication. It has previously been thought that simulation cannot make you a good doctor, communicator or leader. However, the advent of non-technical skills simulation aims to do just that: by practicing and employing these skills within our daily working teams. Studies have shown that training in non-technical skills can improve teamwork and improve patient outcomes. It is hoped that providing more training in non-technical skills, alongside psychometrically robust assessment, can help to develop a new generation of surgeons competent in all the skills required for safe patient care.

\section{Compliance with Ethical Standards}

Conflict of Interest Jennifer Magill and Neil Tolley declare that they have no conflict of interest.

Human and Animal Rights and Informed Consent This article does not contain any studies with human or animal subjects performed by any of the authors.

Open Access This article is licensed under a Creative Commons Attribution 4.0 International License, which permits use, sharing, adaptation, distribution and reproduction in any medium or format, as long as you give appropriate credit to the original author(s) and the source, provide a link to the Creative Commons licence, and indicate if changes were made. The images or other third party material in this article are included in the article's Creative Commons licence, unless indicated otherwise in a credit line to the material. If material is not included in the article's Creative Commons licence and your intended use is not permitted by statutory regulation or exceeds the permitted use, you will need to obtain permission directly from the copyright holder. To view a copy of this licence, visit http://creativecommons.org/licenses/by/4.0/. 


\section{References}

Papers of particular interest, published recently, have been highlighted as:

- Of importance

- Of major importance

1. Gawande AA, et al. Analysis of errors reported by surgeons at three teaching hospitals. Surgery. 2003;133(6):614-21.

2.• Kohn LT, Corrigan JM, Donaldson MS, editors. To Err is Human: Building a Safer Health System. Washington (DC); 2000. This was a landmark publication, which highlighted teamwork as a mechanism for improving patient safety.

3. Department of Health, London. An Organisation with a Memory: learning from adverse events in the NHS. London: The Stationary Office; 2000

4. Thomas EJ, Studdert DM, Burstin HR, Orav EJ, Zeena T, Williams EJ, et al. Incidence and types of adverse events and negligent care in Utah and Colorado. Med Care. 2000;38(3):261-71.

5. Gawande AA, et al. The incidence and nature of surgical adverse events in Colorado and Utah in 1992. Surgery. 1999;126(1):66-75.

6. Flin R, O'Connor P, Crichton M. Safety at the sharp end: a guide to non-technical skills. Aldershot: Ashgate; 2008.

7. Awad Z, Taghi A, Sethukumar P, Tolley NS. Construct validity of the ovine model in endoscopic sinus surgery training. Laryngoscope. 2015;125(3):539-43.

8. Danino J, et al. Patient safety in otolaryngology: a descriptive review. Eur Arch Otorhinolaryngol. 2016.

9. Cook, T.M., Woodall N., Frerk C., Fourth National Audit Project., Major complications of airway management in the UK: results of the Fourth National Audit Project of the Royal College of Anaesthetists and the Difficult Airway Society. Part 1: anaesthesia. Br J Anaesth, 2011. 106(5): p. 617-631.

10. Cook TM, et al. Major complications of airway management in the UK: results of the Fourth National Audit Project of the Royal College of Anaesthetists and the Difficult Airway Society. Part 2: intensive care and emergency departments. Br J Anaesth. 2011;106(5):632-42.

11. Dean KM, et al. Otolaryngology boot camps: current landscape and future directions. Laryngoscope. 2019.

12. Volk MS, et al. Using medical simulation to teach crisis resource management and decision-making skills to otolaryngology housestaff. Otolaryngol Head Neck Surg. 2011;145(1):35-42.

13. Tsai AC, et al. Comprehensive Emergency Airway Response Team (EART) training and education: impact on team effectiveness, personnel confidence, and protocol knowledge. Ann Otol Rhinol Laryngol. 2016;125(6):457-63.

14. Deutsch ES, et al. Multimodality education for airway endoscopy skill development. Ann Otol Rhinol Laryngol. 2009;118(2):81-6.
15. Deutsch ES, Malloy KM, Malekzadeh S. Simulation-based otorhinolaryngology emergencies boot camp: part 3: complex teamwork scenarios and conclusions. Laryngoscope. 2014;124(7):1570-2.

16. Chin CJ, Roth K, Rotenberg BW, Fung K. Emergencies in otolaryngology-head and neck surgery bootcamp: a novel Canadian experience. Laryngoscope. 2014;124(10):2275-80.

17. Hogg ES, et al. A high-fidelity, fully immersive simulation course to replicate ENT and head and neck emergencies. J Laryngol Otol. 2019;133(2):115-8

18. Chin CJ, et al. Simulation-based otolaryngology - head and neck surgery boot camp: 'how I do it'. J Laryngol Otol. 2016;130(3): 284-90.

19. Malekzadeh S, et al. ORL emergencies boot camp: using simulation to onboard residents. Laryngoscope. 2011;121(10):2114-21.

20. Smith ME, Trinidade A, Tysome JR. The ENT boot camp: an effective training method for ENT induction. Clin Otolaryngol. 2016;41(4):421-4.

21. Wu KY, et al. Assessing nontechnical skills in otolaryngology emergencies through simulation-based training. Laryngoscope. 2018;128(10):2301-6. Findings from this study demonstrate that the assessment of non-technical skills in otolaryngology is feasable and reliable. It is the only publication in the literature to date to use a validated tool to assess non-technical skills.

22. Sevdalis N, et al. Reliability of a revised NOTECHS scale for use in surgical teams. Am J Surg. 2008;196(2):184-90.

23. Yule $\mathrm{S}$, et al. Development of a rating system for surgeons' nontechnical skills. Med Educ. 2006;40(11):1098-104.

24. Robertson ER, Hadi M, Morgan LJ, Pickering SP, Collins G, New $S$, et al. Oxford NOTECHS II: a modified theatre team nontechnical skills scoring system. PLoS One. 2014;9(3):e90320.

25. Mishra A, Catchpole K, McCulloch P. The Oxford NOTECHS system: reliability and validity of a tool for measuring teamwork behaviour in the operating theatre. Qual Saf Health Care. 2009;18(2):104-8.

26. Hull L, et al. Observational teamwork assessment for surgery: content validation and tool refinement. J Am Coll Surg. 2011;212(2): 234-243 e1-5.

27. Amin MR, Friedmann DR. Simulation-based training in advanced airway skills in an otolaryngology residency program. Laryngoscope. 2013;123(3):629-34.

28. Smith ME, Navaratnam A, Jablenska L, Dimitriadis PA, Sharma R. A randomized controlled trial of simulation-based training for ear, nose, and throat emergencies. Laryngoscope. 2015;125(8):181621.

29. Mehta N, Boynton C, Boss L, Morris H, Tatla T. Multidisciplinary difficult airway simulation training: two year evaluation and validation of a novel training approach at a District General Hospital based in the UK. Eur Arch Otorhinolaryngol. 2013;270(1):211-7.

Publisher's Note Springer Nature remains neutral with regard to jurisdictional claims in published maps and institutional affiliations. 